\title{
Assessment of Constructed Wetlands' Potential for the Removal of Cyanobacteria and Microcystins (MC-LR)
}

\author{
Guna Bavithra ${ }^{1,2}{ }^{\oplus}$, Joana Azevedo ${ }^{1}$, Flávio Oliveira ${ }^{1}$, João Morais ${ }^{1}$, Edgar Pinto ${ }^{3,4} \oplus$, \\ Isabel M.P.L.V.O. Ferreira ${ }^{3}$, Vitor Vasconcelos ${ }^{1,5}{ }^{\mathbb{D}}$, Alexandre Campos $^{1}$ and \\ C. Marisa R. Almeida 1,*iD \\ 1 CIIMAR - Interdisciplinary Centre of Marine and Environmental Research, University of Porto, Porto, \\ Terminal de Cruzeiros do Porto de Leixões, Avenida General Norton de Matos, S/N, 4450-208 Matosinhos, \\ Portugal; bavi.96@gmail.com (G.B.); joana.azevedo@ciimar.up.pt (J.A.); up201510053@fc.up.pt (F.O.); \\ jmorais@ciimar.up.pt (J.M.); vmvascon@fc.up.pt (V.V.); amoclclix@gmail.com (A.C.) \\ 2 Department of Integrative Biology, School of Biosciences and Technology, Vellore Institute of Technology, \\ Vellore 632014, Tamil Nadu, India \\ 3 LAQV/REQUIMTE-Laboratory of Bromatology and Hydrology, Department of Chemical Sciences, Faculty \\ of Pharmacy, University of Porto, Rua Jorge de Viterbo Ferreira 228, 4050-313 Porto, Portugal; \\ edgarpinto7@gmail.com (E.P.); Isabel.ferreira@ff.up.pt (I.M.P.L.V.O.F.) \\ 4 Department of Environmental Health, School of Health, Politécnico do Porto. CISA/Research Center in \\ Environment and Health, Rua Dr. António Bernardino de Almeida, 400. 4200-072 Porto, Portugal \\ 5 Faculty of Sciences, University of Porto, Rua do Campo Alegre 790, 4150-171 Porto, Portugal \\ * Correspondence: calmeida@ciimar.up.pt
}

Received: 13 November 2019; Accepted: 14 December 2019; Published: 18 December 2019

\begin{abstract}
Microcystis blooms and the subsequent release of hepatotoxic microcystins (MCs) pose a serious threat to the safety of water for human and livestock consumption, agriculture irrigation, and aquaculture worldwide. Microcystin-LR (MC-LR), the most toxic variant of MCs, has been widely detected in a variety of environments such as water, sediments, plants, and many aquatic organisms. Conventional solutions of water treatment are costly, requiring specific infrastructure, as well as specialized personnel and equipment. Therefore, these solutions are not feasible in many rural areas or in the treatment of large reservoirs. In this regard, low-cost and low-technology solutions, such as constructed wetlands (CWs), are attractive solutions to treat surface waters contaminated with toxic cyanobacteria blooms from lakes, ponds, reservoirs, and irrigation systems. In line with this, the main aim of this work was to evaluate the potential of CWs for the treatment of water contaminated with MC-LR produced by Microcystis aeruginosa-LEGE 91094. For that, microcosms $(0.4 \times 0.3 \times 0.3 \mathrm{~m})$ simulating CWs were assembled with Phragmites australis to treat lake water contaminated with Microcystis aeruginosa cells and MCs. Results showed removal percentages of M. aeruginosa cells above $94 \%$ and about $99 \%$ removal of MC-LR during 1 week treatment cycles. CWs maintained their functions, regardless the presence of MC-LR in the system, and also showed significant removal of nutrients (ammonium ion removal up to $86 \%$ ) and organic matter (removal reaching $98 \%$ ). The present work indicates that CWs have the potential for removal of cyanobacterial cells and cyanotoxins, which can be useful for the treatment of eutrophic waters and provide water of sufficient quality to be used, for instance, in agriculture.
\end{abstract}

Keywords: Cyanobacteria; microcystins; rhizoremediation; Phragmites australis; water treatment

\section{Introduction}

Cyanobacteria (previously known as blue-green algae) occur in diverse environments, being highly prevalent in the aquatic environment, for example, in fresh water, brackish water, oceans, and 
hot springs. They are either present as biofilms or benthic mats, or dispersed in the water column as planktonic organisms. In eutrophic waters, cyanobacteria frequently reach high cell densities, forming the so-called blooms [1]. Earlier, cyanobacterial blooms were regarded simply as an aesthetic problem due to their scum-like appearance (green, brown, or red) and strong disagreeable odour. However, cyanobacteria are known to produce different toxins. Cyanotoxin poisoning was first reported in an Australian lake in 1878 [2], and since then the increased frequency of fish death, unknown hepatotoxic/neurotoxic diseases, and animal poisonings have led to an increased research interest and public awareness of harmful cyanobacterial blooms [1].

Cyanotoxins are a very diverse group of toxins including microcystins, anatoxins, cylindrospermopsin, or saxitoxins, and differ in molecular structures and toxic properties. Humans can be exposed to cyanotoxins through various exposure pathways such as through consumption of drinking water (the main form of exposure), dermal contact during recreational purposes, consumption of algal supplements, consumption of fruits or vegetables irrigated with cyanotoxin-contaminated water, consumption of aquatic organisms from contaminated waters, and, in rare cases, through inhalation or contact with nasal mucous membranes while taking showers [3-5]. Microcystins are the most relevant cyanotoxins, belonging to a family of hepatotoxins that are most frequently found in freshwater blooms worldwide. These toxins are primarily produced by Microcystis genera, namely, Microcystis aeruginosa [6]. Microcystis blooms and the release of hepatotoxic microcystins (MCs) pose a serious threat to the safety of water for human and livestock consumption, crop irrigation, and aquaculture worldwide. Microcystin-LR (MC-LR) is the most common and toxic variant of MCs with acute pathogenicity that causes allergic reactions and fatal liver haemorrhage. MC-LR has been widely detected in a variety of environments such as waters, sediments, plants, and some aquatic products, and is also associated to some severe human toxicity incidents. [3].

The scarcity of clean water resources and the need to use closer eutrophic water bodies can lead to the compulsory use in agriculture of water containing cyanobacteria and their toxins [7]. Cyanotoxins can affect plants either by reducing their germination rates [8,9] and growth [10-12] but also they can be taken up by plants and transfer the toxins to humans and other animals via food $[10,13,14]$. This practice is more frequent in arid areas, such as the Mediterranean basin, where the demand for water for irrigation purposes is higher. In these areas, efficient mechanisms for monitoring water quality as well as its treatment should be implemented.

Conventional solutions of water treatment are costly, requiring specific infrastructures, specialized personnel, and equipment and energy to operate. In this regard, a challenge is placed concerning the treatment of surface waters contaminated with toxic cyanobacteria blooms, from lakes, ponds, and reservoirs that supply water for agriculture, where the application of conventional technologies is not economically feasible. In addition, many natural eutrophic waters (surface and ground waters) are localized in rural areas with limited access to infrastructure and electricity. In these cases, low-cost and low-technology solutions become the most appropriate for water treatment.

Natural wetlands purify water by breaking down and assimilating nutrients, bacteria, and other contaminants. Artificial wetlands, the so-called constructed wetlands (CWs), have been constructed to replicate these processes [15]. CWs are complex systems containing water, substrate, plants (e.g., Phragmites australis), and native microorganisms. Physical, chemical, and biological processes, such as volatilization, sorption and sedimentation, photodegradation, plant uptake, and microbial degradation, may occur simultaneously, contributing to the elimination of several types of compounds [16,17]. In fact, CWs have shown a great capability in significantly reducing the concentration of several persisting and emergent water pollutants (e.g., $[15,18,19])$. This concept can also be extended to recover environmental surface and ground waters contaminated with cyanobacteria and cyanotoxins. Such systems would suit the treatment of stored waters in the sub-systems of large reservoirs that, for instance, supply water for agriculture. Furthermore, control of toxic cyanobacteria blooms by CW can be also achieved through removal of excess nutrients in the water, a feature CWs are already known for (e.g., [17,20]). Studies reporting the capability of aquatic plants or microorganism sediment communities to remove/degrade 
different cyanotoxins from water are scarce, but results are encouraging. Experimental studies have shown the capability of aquatic plants to remove the neurotoxin anatoxin-a (ANTX-a) [21] and MCs [22,23], although in some cases with toxic effects to the plants [21]. The capability of sediment microorganisms to degrade MCs has also been described [24], and MC biodegradation can be an option for cyanotoxin removal [23]. It is thus quite clear that both plants and microorganisms are key players in CWs. Recently, Wang et al. [25] reported high removal rates of MC in a microcosm's CW, although tests were made with synthetic water doped with MCs. Thus, tests with real waters are needed to simultaneously monitor other features of CWs such as nutrient removal. Moreover, it is very important that both cells and toxins are removed from the water [1]. Cyanobacteria can release toxins during cell senescence or cell death and lysis, rather than by continuous release during cell growth [22], being important to remove both living cells and the dissolved toxin. To gain more insight into the potential of CWs for the treatment of eutrophic waters contaminated with toxic cyanobacteria, we outline an experiment with a microcosms system assembled with $P$. australis and investigated the removal of toxic M. aeruginosa cells and dissolved MC-LR from eutrophic lake water samples. Within the diversity of MC variants known (over 240 variants) the toxin variant MC-LR was chosen for the experiment because it is one of the most frequently reported in the environment and the most toxic [3].

Although full-scale studies are needed to fully assess possible applications in situ, bench scale studies are generally needed as a first approach to establish test hypothesis such as in the present case. The microcosm approach has shown to suitably represent interactions among plants, microorganisms, substrates, and contaminants within a complex rhizosphere system [26]. As so, current studies were done in microcosms, simulating vertical sub-surface flow CWs with natural lake water. In this CWs type, water flows below the surface of the planted bed substrate and percolates vertically through the entire substrate. In general, CW substrates have different layers, an approach followed in the current study - an inert drainage layer with coarse gravel, a main filter layer that can have sand, lava rock, or other porous material that promotes filtration as well as biofilm formation and microbial activity, and a plant root bed soil/sediment on top into which plants are transplanted.

\section{Materials and Methods}

\subsection{Cyanobacteria Culture}

To prepare the M. aeruginosa culture, permission was granted by Blue Biotechnology and Ecotoxicology Culture Collection (LEGE-CC) to use the strain LEGE 91094 (Microcystis aeruginosa) (https://lege.ciimar.up.pt/culture/microcystis-aeruginosa-lege-91094/). A starter culture was prepared by transferring an aliquot from the LEGE-CC flask to a $50 \mathrm{~mL}$ culture flask under sterile conditions and allowing it to grow for two weeks in $\mathrm{Z} 8$ culture medium [27]. This culture was then transferred to a $450 \mathrm{~mL}$ culture flask. Microscopic examination was carried out to confirm cells were in good, unicyanobacterial conditions before starting to scale up the culture. The scale up of the culture started by adding $450 \mathrm{~mL}$ of the dense starter culture to $4 \mathrm{~L}$ of culture medium in a $6 \mathrm{~L}$ glass culture balloon and allowing it to grow for 2 weeks. Subsequently, $4 \mathrm{~L}$ of this dense culture was added to $16 \mathrm{~L}$ of culture medium in a $20 \mathrm{~L}$ autoclavable flask (NALGENE) and grown for a month before being use in the experiments with the CWs. M. aeruginosa was grown at $25^{\circ} \mathrm{C}$, with a light intensity of $22 \mu \mathrm{mol} \mathrm{m} \mathrm{s} \mathrm{s}^{-1}$, under a light/dark cycle of $14 / 10 \mathrm{~h}$ during all stages. The same conditions were kept to maintain the culture for the experiments with the CWs.

\subsection{Sampling, Microcosm Setup, and Experimental Conditions}

Lake water was collected from a lake in the city park of Porto, Portugal $\left(41^{\circ} 10^{\prime} 3.24^{\prime \prime} \mathrm{N} ; 8^{\circ} 40^{\prime} 36.05^{\prime \prime}\right.$ W) from September 2018 to November 2018, on a weekly basis. A previous study has shown the presence of microcystins, namely MC-LR, in this lake and other lakes of the city park [28]. Collected volumes of lake surface water varied between 12 to $15 \mathrm{~L}$. Plastic bottles that were previously decontaminated 
(washed with deionized water and local water) were used for the water collection. The water was immediately transported to the laboratory where the CW microcosms were kept.

For assembling CW microcosms, $P$. australis plants were collected from the banks of the river Lima, Portugal $\left(41^{\circ} 46^{\prime} \mathrm{N} ; 8^{\circ} 34^{\prime} \mathrm{W}\right)$ in September 2018. The plants were collected with the sediment around its roots (to preserve the plants' rhizosphere) in a $20 \times 20 \times 20 \mathrm{~cm}^{3}$ size cube. The sediment in contact with the plant roots (rhizosediment) was removed on site and plants were washed with estuarine water. The rhizosediment, as well as sand from the river banks, were also collected. In the laboratory, sediment and sand were later mixed in a ratio of 1:2 (sediments/sand) and used as plant root bed substrate in the $\mathrm{CW}$ microcosms.

Experiments were conducted in controlled conditions in microcosms that simulated CWs with subsurface vertical flow. Three CW microcosms were set up in plastic containers $\left(40 \times 30 \times 30 \mathrm{~cm}^{3}\right)$, each consisting of four layers: $1 \mathrm{~cm}$ of big gravel, $4 \mathrm{~cm}$ of small gravel, $2 \mathrm{~cm}$ of lava rock, and $8 \mathrm{~cm}$ of root bed substrate (sediments and sand in proportion 1:2) into which P. australis was transplanted. Each microcosm had ca. 40 sprouts, to have a significant plant-root effect on the water treatment. The plastic containers were wrapped with aluminium foil to prevent sunlight exposure and to avoid possible photo-degradation of the compounds. For the acclimation of the microcosms, $1.5 \mathrm{~L}$ of Hoagland nutrient solution was added every two days for two weeks before the start of the experiments. The level of the solution was kept just above the soil surface. For the experiments, circulating tubes with pumps were placed in each container to promote water circulation in the microcosms. More details are provided in Gorito et al. [26]. Microcosms were kept under greenhouse-like conditions (in the Chemistry Department, Faculty of Science, University of Porto), namely, natural day/night regime, with a temperature variation between 15 to $25^{\circ} \mathrm{C}$, between September and November 2018.

\subsection{CW Experiments}

For the $\mathrm{CW}$ experiments, $3500 \mathrm{~mL}$ of lake water was added to each $\mathrm{CW}$ microcosm. After the 2 weeks of acclimation with nutrient solution, fresh lake water was added to the microcosms. This process was repeated for 2 weeks for acclimation of the system. In the following weeks, as the lake water had very low levels of both MC-LR and M. aeruginosa, the lake water was contaminated with cyanobacteria cells and toxins. For the third week, lake water was spiked with the M. aeruginosa culture (MC-LR-producing culture grown as described above) at a cell density of half of the density of $10^{6}$ cells $/ \mathrm{mL}$ and MC-LR concentration of ca. $25 \mu \mathrm{g} / \mathrm{L}$, for CWs adaptation. The M. aeruginosa culture had a cell density of ca. $2 \times 10^{7}$ cell//mL and a concentration of MC-LR of ca. $1 \mathrm{mg} / \mathrm{L}$. From the fourth week onwards, the lake water was spiked with a final cell density of ca. $10^{6}$ cells/mL and MC-LR concentration of ca. $50 \mu \mathrm{g} / \mathrm{L}$. This cell density has been found already in a natural cyanobacterial bloom of $M$. aeruginosa $[22,28]$. Moreover, spiking the water with live cyanobacterial cells rather than just toxins (which are dissolved in water) adds ecological relevance to the study, as eutrophic lakes have both cyanotoxins and cyanobacteria cells and both need to be removed. Spiked water was also left to circulate in the system for 1 week. After that period, the treated water was removed and the fresh lake water spiked with cyanobacteria culture was added again to the system. This process was repeated five times, taking 5 weeks in total.

\subsection{Samples Collection and Processing}

After each 1 week treatment in CW microcosms, water samples were collected and stored in dark glass bottles. The volume of the treated water coming out of each CW microcosm was measured, and deionised water $(600-800 \mathrm{~mL})$ was added to make up the initial volume of $3500 \mathrm{~mL}$ introduced in CWs to compensate the loss of water through evaporation and uptake by plants. The bottles were homogenized by shaking them well.

For MC-LR analysis, $1 \mathrm{~L}$ of lake water or CW-treated water was filtered through glass fibre filters $\left(1.2 \mu \mathrm{m}\right.$ diameter). The filters were wrapped in aluminium foils and stored at $-20^{\circ} \mathrm{C}$. Between $500-800 \mathrm{~mL}$ of the filtered water was stored in decontaminated glass bottles at $-20^{\circ} \mathrm{C}$. 
For nutrient analysis, $40-45 \mathrm{~mL}$ of filtered water was stored in decontaminated (acid washed) falcons and kept at $-20^{\circ} \mathrm{C}$.

For cyanobacteria count, $2 \mathrm{~mL}$ of filtered water was kept in microtubes (containing Lugol solution).

Organic matter analysis, through chemical oxygen demand (COD), was carried out in collected water (unfiltered, $2 \mathrm{~mL}$ ) on the day of collection.

At the end of the experiment, samples of sediment (about $15 \mathrm{~g}$ ) from each $\mathrm{CW}$ microcosm were also collected for toxin analysis. From each microcosm, three pools of root bed substrate (along with roots depth) were collected, homogenized, and stored in aluminium foil at $-20^{\circ} \mathrm{C}$ until toxin analysis.

\subsection{MC-LR Extraction}

The procedure for MC-LR extraction from the lake water and treated water was adapted from Lawton et al. [29], and Ramanan et al. [30], with slight modifications.

MC-LR extraction was performed both on the dissolved (filtrate water) and suspended matter (retained in the filter during water filtration).

For MC-LR extraction, the filters were put in beakers and $10-15 \mathrm{~mL}$ of $50 \%$ methanol $(v / v)$, sufficient for immersion of filters, was added. The solution was then subject to ultrasound $(60 \mathrm{~Hz}, 5 \times 1 \mathrm{~min})$ using a probe sonicator (Vibra cell, Sonics and Materials, Danbury, CT, USA) to help homogenize, as well as to perform cell lysis. Centrifugation (Gyrozen-2236R High-Speed Centrifuge, Gochon-eup, Korea) was done consequently at a speed of $6000 \mathrm{rpm}$ for $5 \mathrm{~min}$ at $4{ }^{\circ} \mathrm{C}$. The supernatant was collected and kept overnight at $4{ }^{\circ} \mathrm{C}$. The extracted filter was also kept at $4{ }^{\circ} \mathrm{C}$. Another cycle of extraction was done the next day and supernatants pooled together. The supernatant was evaporated to dryness using a rotavapor. The residues were then re-suspended in $1 \mathrm{~mL}$ solution of $50 \%$ methanol (LC-MS grade), acidified with $0.1 \%$ trifluoroacetic acid (TFA), centrifuged at $12 \mathrm{rpm}$ for $5 \mathrm{~min}$ to remove tiny debris of filters, and transferred to a $2 \mathrm{~mL}$ glass vial.

The filtered water samples were defrosted and subsequently homogenized by shaking. These samples were subject to solid-phase extraction (SPE) to concentrate and purify the samples using Oasis HLB cartridges ( $3 \mathrm{~mL}, 3 \mathrm{cc}$ ) from Waters Corporation (Millford, MA, USA) in a ManiFold vacuum system (Supelco, Madrid, Spain). Briefly, the cartridges were conditioned with $5 \mathrm{~mL}$ of methanol, followed by $5 \mathrm{~mL}$ of deionized water. Then, the samples were loaded. Afterward, the cartridges were cleaned with $5 \mathrm{~mL}$ of methanol/water $(5: 95 \mathrm{v} / \mathrm{v})$ and left to dry for $30 \mathrm{~min}$. For the elution, $5 \mathrm{~mL}$ of methanol/formic acid $(95: 5 \mathrm{v} / \mathrm{v})$ solution was used. The eluted samples were stored at $-20^{\circ} \mathrm{C}$ overnight and evaporated to dryness the next day using a rotavapor. The residue was re-suspended in $1 \mathrm{~mL}$ solution of $50 \%$ methanol (LC-MS grade), acidified with $0.1 \%$ TFA, and transferred to a $2 \mathrm{~mL}$ HPLC vial. Tests were made with samples with a known amount of MC-LR toxin to evaluate SPE recoveries, which were $96 \pm 8 \%$.

MC-LR extraction from the CW sediments was carried out following the procedure from Machado et al. [11] with certain modifications. An extraction solvent of $80 \%$ methanol $(v / v)$ with $0.1 \%(v / v)$ TFA was prepared. The sediment samples were homogenized with the extraction solvent in a ratio of 1:5 (3 $\mathrm{g}$ of sediment and $15 \mathrm{~mL}$ of extraction solvent) using a vortex. The homogenate was allowed to stand in a shaking incubator for 1 hour to increase the extraction of MC-LR. Subsequently, the sample was probe sonicated (Vibracell) for $5 \mathrm{~min}$ at $60 \mathrm{~Hz}$ and then centrifuged for $20 \mathrm{~min}$ at $4{ }^{\circ} \mathrm{C}$ with an rpm of $4495 \mathrm{~g}$ (Gyrozen-2236R High-Speed Centrifuge). The supernatant was then collected and evaporated to dryness with the use of a rotavapor. The residues were then re-suspended in $1 \mathrm{~mL}$ solution of $50 \%$ methanol (LC-MS grade), acidified with $0.1 \%$ TFA, and transferred to a $2 \mathrm{~mL}$ glass vial.

High Pressure Liquid Chromatography with Photometric Diode Array (HPLC-PDA) detection and Liquid Chromatography coupled to Tandem Mass Spectrometry (LC-MS/MS) were then performed to check the presence and quantify the amount of MC-LR both on the dissolved and on the suspended matter of the water samples, as well as on CW sediments.

LC-MS/MS was used whenever MC-LR concentrations were below the HPLC-PDA detection limit. 


\subsection{Detection and Quantification of MC-LR by HPLC-PDA}

Samples were injected on an HPLC system equipped with a PDA detector-Waters Alliance 2695 (Waters, Milford, MA, USA). The chromatographic column was a reverse-phase Merck Lichrospher $\mathrm{RP}-18$ endcapped column $(250 \times 4.6 \mathrm{~mm}$ internal diameter, $5 \mu \mathrm{m})$, equipped with a guard column $(4 \times 4 \mathrm{~mm}, 5 \mu \mathrm{m})$ both kept at $45^{\circ} \mathrm{C}$. Two mobile phases were used: $(\mathrm{A})$ methanol $+0.1 \%$ TFA and (B) $\mathrm{H}_{2} \mathrm{O}+0.1 \%$ TFA. The linear gradient elution consisted of $55 \% \mathrm{~A}$ and $45 \% \mathrm{~B}$ at $0 \mathrm{~min}, 65 \% \mathrm{~A}$ and $35 \% \mathrm{~B}$ at $5 \mathrm{~min}, 80 \% \mathrm{~A}$ and $20 \% \mathrm{~B}$ at $10 \mathrm{~min}, 100 \% \mathrm{~A}$ at $15 \mathrm{~min}$, and $55 \% \mathrm{~A}$ and $45 \%$ B between 15.1 and $20 \mathrm{~min}$, with a flow rate of $0.9 \mathrm{~mL} / \mathrm{min}$. The injected volume was $20 \mu \mathrm{L}$. The PDA range was 210-400 nm, with a fixed wavelength at $238 \mathrm{~nm}$. The MC-LR was identified by comparison of spectra and retention time of a standard solution of MC-LR (code: CRM-03-CYN, batch $\mathrm{n}^{\circ}$. 15-001, 11.5 \pm $0.7 \mu \mathrm{g} / \mathrm{mL}$ of MC-LR in $0.5 \mathrm{~mL}$ methanol, Laboratorio CIFGA S.A). The system was calibrated by using a set of seven dilutions of MC-LR standard solution (in a concentration range of 0.5 to $10 \mu \mathrm{g} / \mathrm{mL}$ ) in methanol 50\% solution. Each vial was injected in duplicate and every HPLC run series of 10 samples included a blank solution (signal always below detection limit) and two different MC-LR standard solutions. Empower 2 Chromatography Data software was used for calculation and reporting peak information. The limit of detection (LOD) and quantification (LOQ) of MC-LR were 0.3 and $0.5 \mu \mathrm{g} / \mathrm{mL}$, respectively. Taking into consideration the SPE step, the LOD and LOQ in the dissolved phase were 0.6 and $1 \mu \mathrm{g} / \mathrm{L}$, respectively. Considering the MC-LC in the filters (ca. $1 \mathrm{~L}$ of water filter), LOD and LOQ in the particulate phase were 0.3 and $0.5 \mathrm{ng} / \mathrm{g}$.

All HPLC solvents were filtered (Pall GH Polypro $47 \mathrm{~mm}, 0.2 \mu \mathrm{m}$ ) and degassed by ultrasound bath.

\subsection{Detection and Quantification of MC-LR by LC-MS/MS}

MC-LR analysis by LC-MS/MS was performed on a Waters 2695 XE separation module coupled to a Waters Micromass Quattro micro Atmospheric Pressure Ionization (API) triple quadrupole mass analyser (Waters, Manchester, United Kingdom). Chromatographic separation was achieved with a core-shell Kinetex C18 column (i.d. $2.1 \times 100 \mathrm{~mm}$, particle size $2.6 \mu \mathrm{m}$ ) fitted with a Security Guard C18 HPLC pre-column, $3 \times 4 \mathrm{~mm}$. The columns were kept at $40^{\circ} \mathrm{C}$ during analysis, and the injection volume was $25 \mu \mathrm{L}$. Mobile phase A was 1\% formic acid (FA) in Milli-Q water and mobile phase B 1\% FA in acetonitrile (ACN). The solvent gradient program was as follows: (1) 0-0.5 min, 10\% B; (2) 0.5-5.5 min, $95 \% \mathrm{~B}$; (3) 5.5-7.5 $\mathrm{min}, 95 \% \mathrm{~B}$; (4) 7.5-9.0 min, 10\% B. After reaching the initial conditions, the column was re-equilibrated for 5 min before the next injection. All organic solvents were of HPLC grade.

Quantification of MC-LR was performed in multiple reaction monitoring (MRM) mode using a triple quadrupole mass spectrometer (MS/MS). The MS was used in positive electro-spray mode (ES+). The optimized MS parameters were as follows: capillary voltage, $3.5 \mathrm{kV}$; source temperature, $130{ }^{\circ} \mathrm{C}$; desolvation temperature, $500{ }^{\circ} \mathrm{C}$; desolvation gas flow, $700 \mathrm{~L} / \mathrm{h}$; cone gas, $50 \mathrm{~L} / \mathrm{h}$; and multiplier, $650 \mathrm{~V}$. High purity nitrogen ( $\geq 99.999 \%)$ and argon $(\geq 99.999 \%)$ were used as the desolvation/cone and collision gases, respectively. The precursor and product ions as well as the cone voltage and collision energy for MC-LR analysis were determined by flow injection analysis. MRM transitions, cone voltage, and collision energies for MC-LR are listed in Table S1 in the Supplementary Materials section. The dwell time for each function was $100 \mathrm{~ms}$. Data acquisition was performed using the Mass Lynx V4.1 software.

Criteria for positive identification and quantification of MC-LR were set in accordance with the guidance document on analytical quality control and method validation procedures for pesticide residues and analysis in food and feed SANTE/11813/2017. MC-LR was considered positively identified in samples when the relative intensities of the quantification product ion in relation to the qualifier product ion, expressed as the ion ratio, differed no more than $\pm 30 \%$ of the ion ratio of the calibration standards. Samples were quantified by interpolation using weighted linear regression $(1 / x)$ and a minimum of five calibration points with triplicate injections of calibration standards.

Calibration standards were prepared from a stock solution of MC-LR (100 $\mu \mathrm{g} / \mathrm{mL})$ in 10\% ACN (1\% FA). Because no ${ }^{13} \mathrm{C}$ or ${ }^{15} \mathrm{~N}$ labelled standards were available, sulfadimethoxine $(100 \mu \mathrm{g} / \mathrm{L}$ in methanol $50 \%, v / v$ ) was used as internal standard. Sulfadimethoxine (VETRANAL, analytical standard), was 
purchased from Sigma-Aldrich (Steinheim, Germany). A specific set of samples was used to determine the validity of using sulfadimethoxine as internal standard (IS). For this purpose, the standard addition method was performed with the addition of known amount of the MC-LR standard. Matrix effects were evaluated by comparing the slopes of the calibration curves and the actual concentrations obtained in the selected samples by IS and standard additions methods. Validation parameters are shown in Table S2. The LOD and LOQ of MC-LR were 2.8 and $10 \mathrm{ng} / \mathrm{mL}$, respectively. Taking into consideration the SPE step, the LOD and LOQ in the dissolved phase were 5.6 and $20 \mathrm{ng} / \mathrm{L}$, respectively. Considering the MC-LC in the filters (ca. $1 \mathrm{~L}$ of water filter), LOD and LOQ in the particulate phase were 2.8 and $10 \mathrm{ng} / \mathrm{L}$. For sediments, the LOD and LOQ were 0.7 and $2.7 \mathrm{ng} / \mathrm{g}$, respectively.

\subsection{Quantification of Cell Density}

Cell counts were done in samples from the first week to the last week of the experiment, in both lake and CW-treated water using a light microscope (Leica) and a Neubauer chamber. Cell density was calculated considering the dilution factor in number of cells $/ \mathrm{mL}$.

\subsection{Nutrient and Organic Matter Analysis}

For nutrient analysis (nitrate ion, ammonium ion, and phosphate ion), samples were defrosted and shaken for homogenization. Nitrate and phosphate in lake and CW-treated waters were measured using kits HI93766-50 and HI93758C, respectively, from Hanna Instruments Portugal. Dissolved ammonium in lake and CW-treated waters was analysed following the method described in Grasshoff et al. [31].

Organic matter content was measured through COD using kits HI93754A-25 and HI93754B-25, low range (LR) (0 to $150 \mathrm{mg} / \mathrm{L}$ ) and medium range (MR) (0 to $1500 \mathrm{mg} / \mathrm{L}$ ), respectively, from Hanna Instruments Portugal. Due to technical reasons, the lake water from week 6 and treated water from week 5 could not be analysed for organic matter.

\subsection{Statistical Analysis}

Samples from each microcosm were treated independently. Afterwards, the mean and standard deviation of the three microcosms' results was calculated.

Significant $(p<0.05)$ differences among samples were evaluated through a parametric one-way analysis of variance (ANOVA) followed by Tukey's pairwise comparisons test.

\section{Results}

\subsection{Removal of Toxin Microcystin and Microcystis aeruginosa Cells in CW Microcosms}

The MC-LR concentrations in the lake water varied between 0.21 to $4 \mu \mathrm{g} / \mathrm{L}$ in the 7 weeks of sampling. In general, values were below $1 \mu \mathrm{g} / \mathrm{L}$, reaching $4 \mu \mathrm{g} / \mathrm{L}$ in only one of the weeks. Moreover, cell densities ranged from $0.04 \times 10^{6}$ cells $/ \mathrm{mL}$ to $0.1 \times 10^{6}$ cells $/ \mathrm{mL}$.

During the 2 weeks of acclimation, MC-LR removals in CWs were higher than $90 \%$. After this acclimation, the lake water was doped with $M$. aeruginosa culture. Results showed an average of $97.3 \%$ removal of the cells by the CW microcosms over 5 weeks (Figure 1), with few cells (between 0.5 and $4.5 \%$ of the initial number of cells) still being found in the water treated by CW microcosms. Removal percentages were identical over time, indicating that a significant percentage of the initially introduced cells were retained in the CWs. 


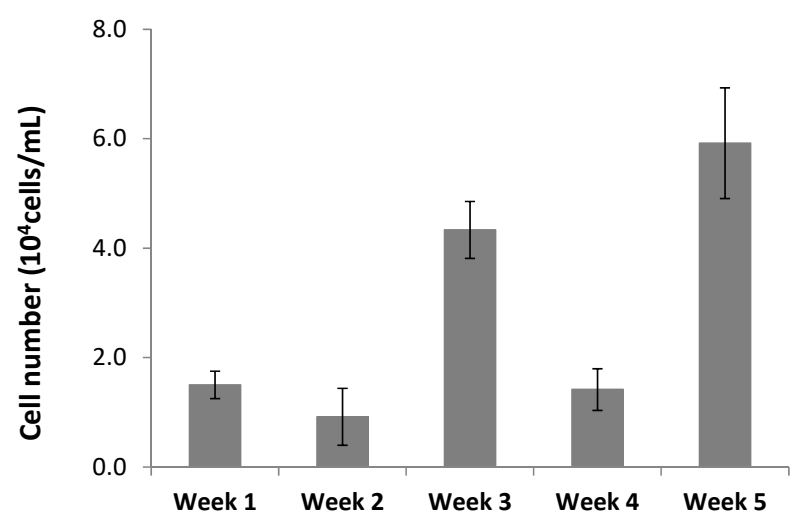

(a)

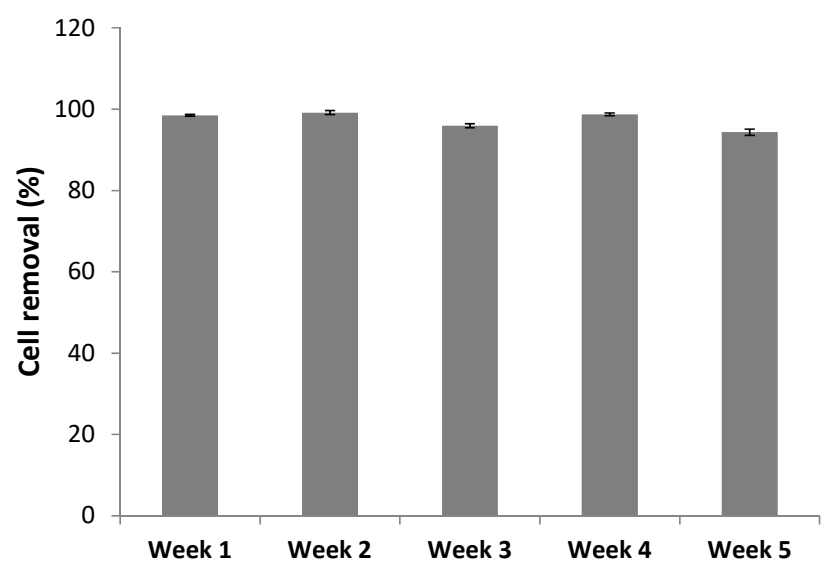

(b)

Figure 1. Quantification of Microcystis aeruginosa cells in the treated water (a) and percentage of removal of cells during constructed wetland (CW) treatment $(\mathbf{b})$ (mean and standard deviation, $n=3$ ). Lake water was spiked with $10^{6}$ cells/mL of $M$. aeruginosa before introduction into $\mathrm{CW}$ microcosms.

The MC-LR concentration in the dissolved phase and suspended matter of water, as well as the sum of MC-LR detected in both phases, is shown in Table 1. The removal percentage of MC-LR from the water by the CWs was higher than $99 \%$, indicating that MC-LR was retained in the CWs. The toxin was either dissolved or attached to the suspended particles, or remained in the cells, with no clear pattern of distribution over time.

Table 1. MC-LR concentrations (mean and standard deviation, $n=3$ ) in CW treated lake water, in dissolved phase, suspended phase, and sum of MC-LR detected in the dissolved phase and suspended matter, and removal percentages. The lake water was spiked with $M$. aeruginosa culture before CW treatment.

\begin{tabular}{ccccc}
\hline Week & $\begin{array}{c}\text { CW-Treated Water } \\
\text { Sum }(\mu \mathrm{g} / \mathrm{L})\end{array}$ & $\begin{array}{c}\text { CW-Treated Water } \\
\text { Dissolved Phase }(\mu \mathrm{g} / \mathrm{L})\end{array}$ & $\begin{array}{c}\text { CW-Treated Water } \\
\text { Suspended Phase }(\mu \mathrm{g} / \mathrm{L})\end{array}$ & $\begin{array}{c}\text { MC-LR Removal } \\
\mathbf{( \% )}\end{array}$ \\
\hline 1 & $0.056(0.009)$ & $0.056(0.009)$ & n.d. ${ }^{*}$ & $99.966(0.006)$ \\
2 & $0.013(0.012)$ & n.d. ${ }^{*}$ & $0.013(0.012)$ & $99.98(0.02)$ \\
3 & $0.205(0.248)$ & $0.062(0.107)$ & $0.143(0.140)$ & $99.93(0.09)$ \\
4 & $0.126(0.089)$ & $0.085(0.074)$ & $0.041(0.021)$ & $99.98(0.01)$ \\
5 & $0.095(0.095)$ & n.d. ${ }^{*}$ & $0.095(0.095)$ & $99.92(0.08)$ \\
\hline
\end{tabular}

n.d. * - not detected, i.e., below detection limit: $5.6 \mathrm{ng} / \mathrm{L}$ for the dissolved phase and $2.8 \mathrm{ng} / \mathrm{L}$ in the particulate phase. 
The MC-LR concentration in the sediments collected at the end of the experiment was $0.03 \pm 0.01$ $\mu \mathrm{g} / \mathrm{g}_{\text {sediment }}$.

\subsection{Removal of Nutrients and Organic Matter in CW Microcosms}

Total organic matter was analysed through COD measurement. Values of COD in the lake water varied from 9 to $83 \mathrm{mg} / \mathrm{L}$ along the sampling weeks (Figure 2). In the CW treated waters, COD values varied between $<\mathrm{LOD}$ to $78 \mathrm{mg} / \mathrm{L}$. The COD levels in lake water were higher in the last 4 weeks than in the first weeks of collection, which could be due to the rise in rainfall patterns and fluctuating temperatures from mid-October to November 2018 [32], which can increase run-off and consequent contamination of the lake. In the two weeks that preceded the experiment, in which non-doped lake water was added to $\mathrm{CW}$ microcosms, COD levels were higher in the $\mathrm{CW}$-treated water than in lake water, probably due to system adaption. In the weeks with lake water spiked with cyanobacterial culture, the treated water showed a consistent decrease in COD levels. At the end of the experiment, CW-treated water showed non-detectable levels of COD, corresponding to removal percentages of organic matter higher than $98 \%$.

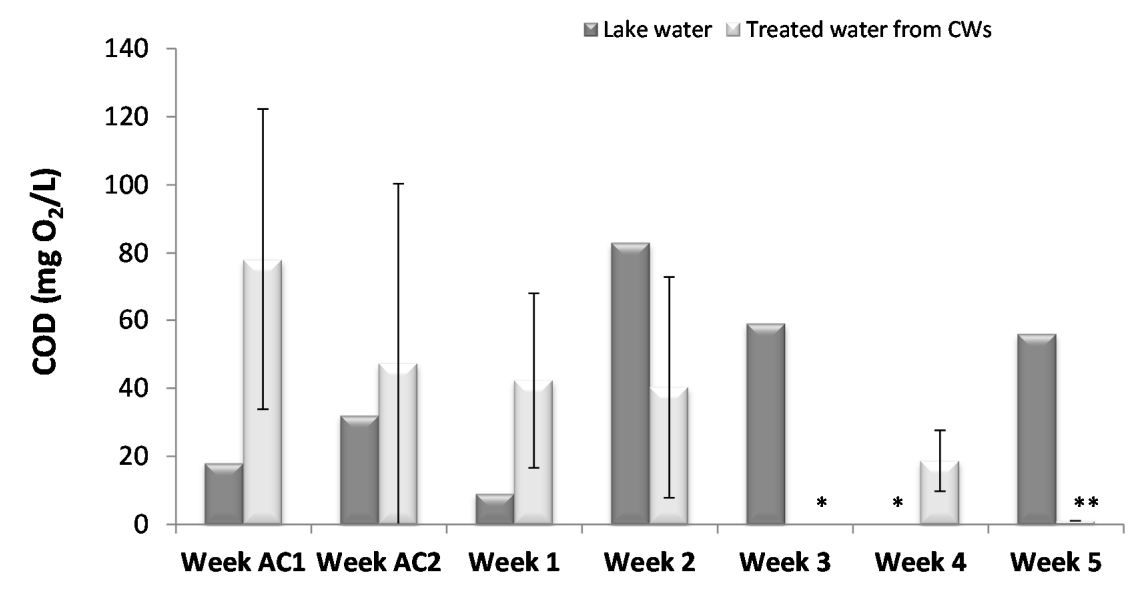

(a)

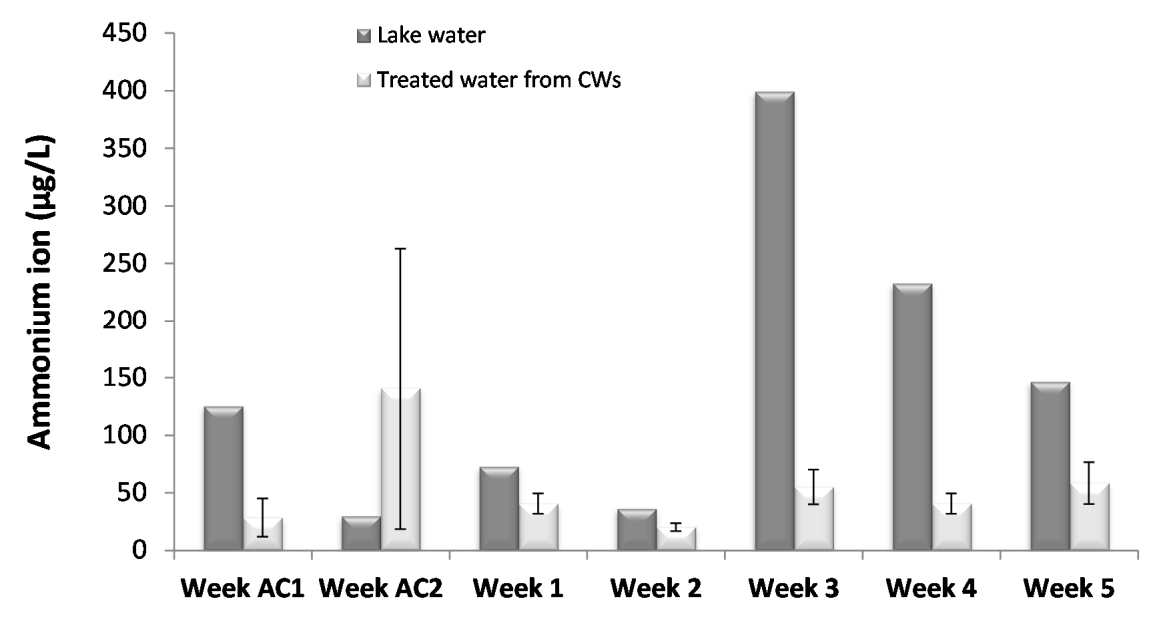

(b)

Figure 2. (a) Chemical oxygen demand (COD) concentrations and (b) ammonium ion concentrations in lake water and in CW-treated water along the sampled weeks. ${ }^{*}$ Due to technical problems, the treated water of week 3 and lake water of week 4 could not be analysed for COD. ** The treated water from $\mathrm{CW}$ in week 5 had non-detectable levels of COD $(<1 \mathrm{mg} / \mathrm{L})$. Week AC1 and Week AC2 indicate the first two weeks of system acclimation. 
Ammonium concentrations in the lake water varied from 29.8 to $399 \mu \mathrm{g} / \mathrm{L}$ and between 28.6 to $140.7 \mu \mathrm{g} / \mathrm{L}$ in the CW-treated waters along the experimental period (Figure 2). Similar to COD, higher ammonium levels in lake water collected in the last weeks were observed, possibly because of the increase in rainfall and fluctuating temperatures from mid-October to November 2018 [32]. The removal percentages of ammonium varied between $44 \%$ to $86 \%$, with removal rates being higher during the experiments with doped lake water when the system was adapted to the water conditions.

The nitrate levels in lake water ranged from 17.7 to $99.7 \mathrm{mg} / \mathrm{L}$ and from 46.4 to $81.8 \mathrm{mg} / \mathrm{L}$ in CW-treated water (Figure 3). Nitrate levels in lake water showed the same behaviour of ammonium probably due to the mentioned metrological parameters. No nitrate removals were observed, with the ion being even excreted from CW in the first acclimation weeks.

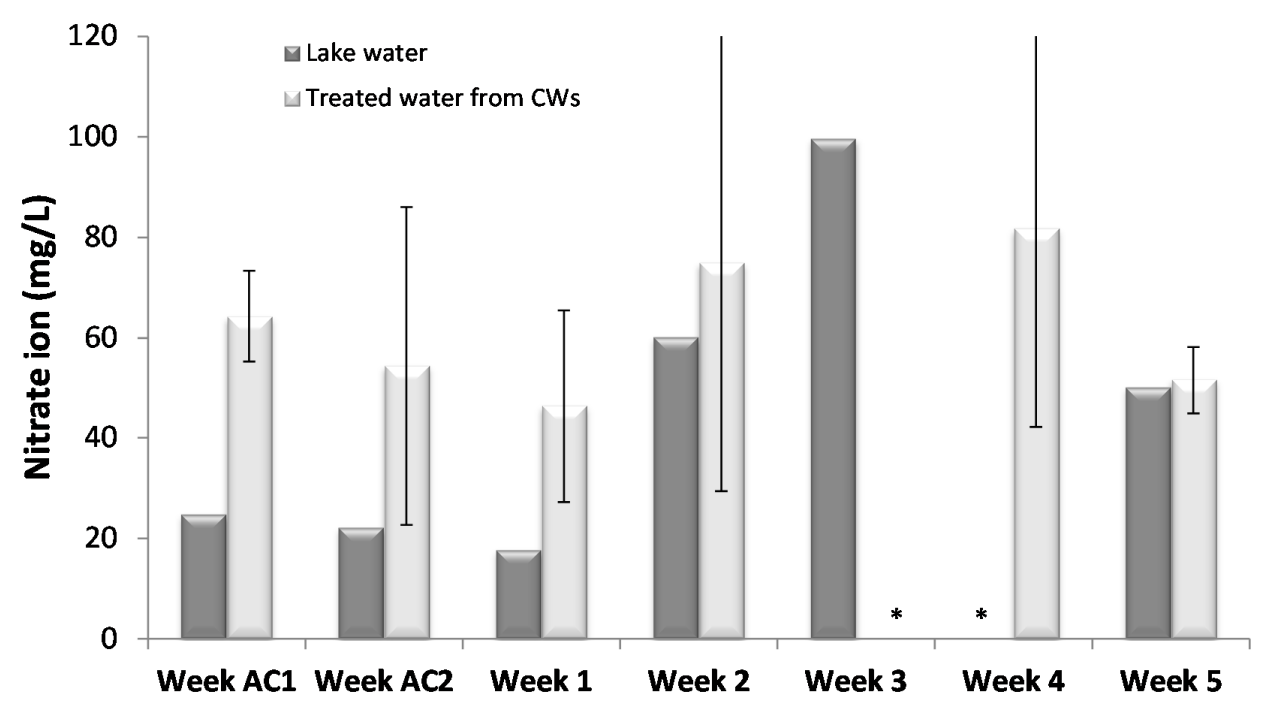

(a)

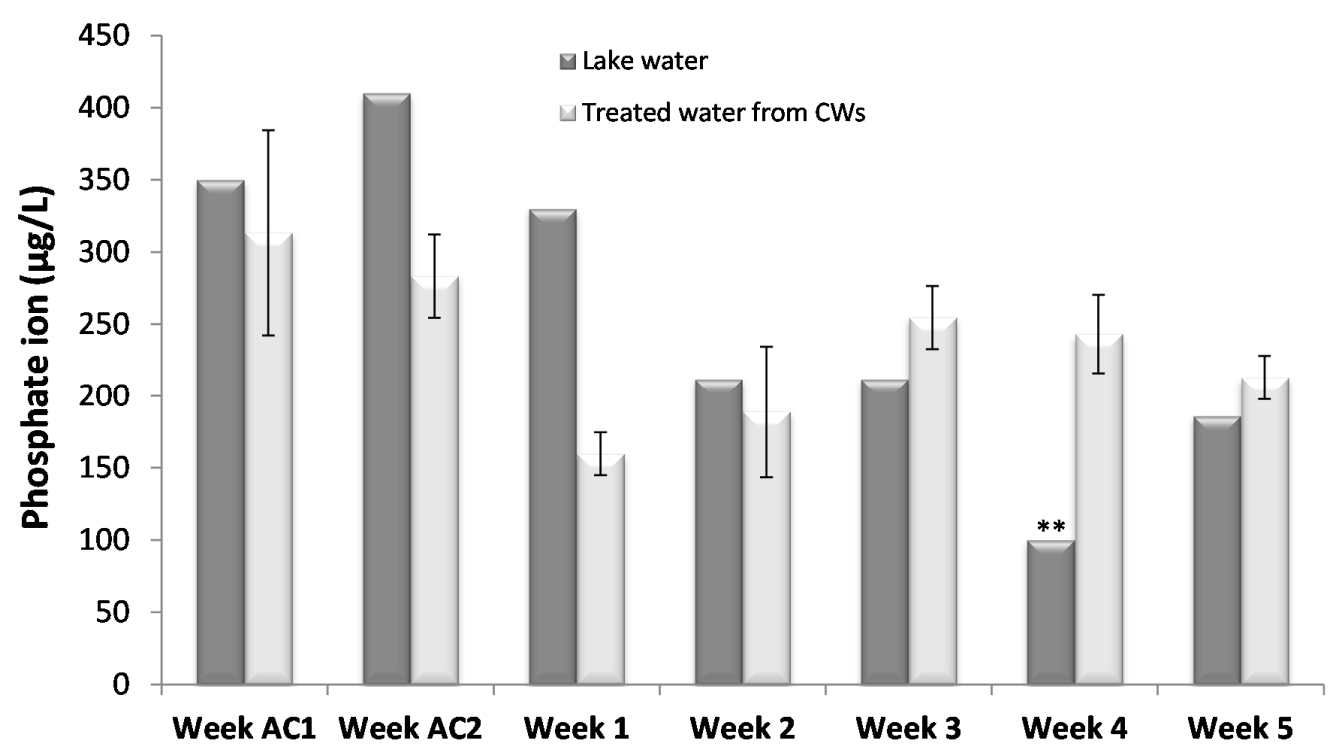

(b)

Figure 3. (a) Nitrate ion concentration and (b) phosphate ion concentration in lake water and in CW-treated water along the sampling weeks. ${ }^{*}$ Due to technical problems, the treated water of week 3 and lake water of week 4 could not be analysed for nitrates. ${ }^{* *}$ The lake water sample from week 4 had a phosphate value below the limit of detection (LOD) $(<100 \mu \mathrm{g} / \mathrm{L})$. Week AC1 and Week AC2 indicate the first two weeks of system acclimation. 
The levels of phosphate in the lake water varied between 185 and $410 \mu \mathrm{g} / \mathrm{L}$ and between 159 and $313 \mu \mathrm{g} / \mathrm{L}$ in the CW-treated water (Figure 3). Values in lake water were higher in the first sampling weeks, contrary to what was observed for ammonium and organic matter contents. The removal of phosphate by the CWs varied between $10 \%$ and $52 \%$ during the first 3 weeks. For the remaining weeks, no phosphate removal was observed.

\section{Discussion}

The current work aimed to test the potential of removing both cyanotoxins and cyanobacteria cells, as these pollutants can be harmful to the environment and can compromise water use, including irrigation.

Tests were carried out with lake water contaminated with a M. aeruginosa culture that contained both cyanobacteria cells (M. aeruginosa) and microcystins (MC-LR). M. aeruginosa is widely found associated with cyanobacteria bloom, specifically in many freshwater bodies across Portugal, including in the lake water of the city park of Porto [28]. A primary role of CWs is the removal of organic matter and nutrients. In the present study, high removal percentages were observed for both organic matter and ammonium after adaption of the system to the lake water and its stabilization, a feature previously observed [33]. Organic matter removal results from a combination of physical and microbial mechanisms, namely, physical retention in the substrate, which results in microorganisms' proliferation and biodegradation [34]. Moreover, plants can also positively influence this removal by stimulating microbial activity [20]. An important issue in CWs is the choice of the plant species because they mediate important processes [35]. For instance, plants can release oxygen through their roots, promoting bacteria activity, bacteria often involved in nitrogen, and carbon cycles. Furthermore, nutrient bioavailability affects plant growth and resource allocation, which influences CW removal efficiency. Thus, in the present work, the plant $P$. australis was chosen. This plant has been commonly used in CWs and has shown a positive role on pollutant removal in these systems [36,37], showing a high capacity to tolerate and remove some pollutants from contaminated waters (e.g., [38]).

Ammonium removal processes also include a combination of physical and microbial mechanisms, although for this compound microbial mechanisms (nitrification coupled with denitrification) seems to be the major removal process [17]. Nitrate removal also depends on denitrification processes, which in the present study were not effective as no significant nitrate removal was observed. Denitrification is the process in which nitrate is converted into dinitrogen via intermediate nitrite, nitric oxide, and nitrous oxide [33]. This result was expected as CWs with vertical water flow are known for their low nitrate removal rates.

Regarding phosphorus, no significant removals were observed, probably due to its low levels. Phosphorus cycle is fundamentally different from nitrogen cycle. Major phosphorus removal processes are sorption, precipitation, and plant uptake [17]. Sorption processes are controlled by the concentration of phosphate in soil porewater and the ability of the solid phase to replenish phosphate into soil porewater. Thus, it was likely that the low levels in the water were similar to those in substrate porewater not resulting in phosphorus removal. Plant uptake also did not seem significant. The presence of cyanobacteria and cyanotoxins could have also affected phosphorus removal. Corbel et al. [22] reported a negative correlation between total phosphorous (TP) and MC concentration in aquatic/soil ecosystems. There may have been lesser uptake of phosphorous from plants due to the presence of cyanobacteria and cyanotoxins.

In general, although $\mathrm{CW}$ operating conditions and influent loads can influence the rates of elimination of nutrients and removal yields might vary considerably, in the present study, organic matter and ammonium removal rates were similar to those already reported for bench-scale [33] and full-scale $[17,20] \mathrm{CW}$ systems. Thus, the CW microcosms assembled were working adequately, simulating a real CW system throughout the experimental period.

Present CW microcosm systems showed high removal rates of MC-LC (>99\%), and the present values were higher than the ones reported by Wang et al. [25] (up to 90\%) when testing removal of MC 
from doped synthetic water in CW systems. There are many possible ways in which the MCs could have been processed in the CWs. CW performance is accomplished by a synergic combination of physical, chemical, and biological (microbial) mechanisms. In fact, several studies have shown that removal of pollutants in CWs occurs mainly by substrate adsorption, microbial biodegradation, and plant uptake, in a combined action of substrate, microorganisms, and plants $[39,40]$, which, in the present study, can be responsible for cyanotoxin removal from the contaminated waters. Studies have shown that once the cyanotoxins enter into aquatic or soil ecosystems they can undergo photochemical degradation by UV, absorption onto sediments or suspended solids, and biodegradation by microorganisms [22]. In this study, the CWs in the plastic containers were wrapped in aluminium foil to prevent any kind of sunlight exposure and photodegradation of compounds. Corbel et al. [22] reported that even with full sunlight exposure it takes at least 2 to 6 weeks for photochemical degradation. Therefore, photochemical degradation was probably not a significant removal mechanism, although slight photochemical degradation on the surface of the CWs during the recirculation of the water cannot be excluded.

Removal of microcystins from the contaminated water may have occurred through physical separation by the CW substrate. Rapala et al. [41] and Lahti et al. [42] reported that no more than $20 \%$ of cyanotoxins can be adsorbed on sediments. In the present study, MC was detected in the root bed substrate at the end of the experiment, ca. $0.033 \mu \mathrm{g} / \mathrm{g}$, indicating MC probable adsorption. Considering the inputs of MC in the water going into the CWs along the 7 weeks and making an estimation of the mass of substrate used in the current systems [26], it can be estimated that ca. half of the MC-LR amount remained adsorbed to the substrate. Therefore, part of the MC_LR was probably biodegraded by microorganisms present in root bed substrate or taken up by plants, although adsorption of the MC-LR onto lava rocks (a porous material that promotes adsorption as well as biofilm formation), not analysed in the present study, cannot be discarded.

Retention in the substrate would have increased breakdown by the microbial community present in the wetland substrate and in biofilms [22]. The presence of plants (P. australis) in the CWs can also increase the microbial activity, for instance through release of exudate compounds, leading to increased removal by biodegradation of pollutants, in the present case microcystins, along with other organic matter [20]. As mentioned above, plants can also biostimulate the microbial rhizosphere by rhizosphere aeration [33]. Thus, biodegradation can be a significant MC removal process in CWs. Studies have indicated that biodegradation can, in fact, be the main fate for the removal of most cyanotoxins in aquatic systems $[22,23]$ and CWs were designed to mimic natural wetlands processes. Several microorganisms have been identified as MC degraders, such as Proteobacteria and Actinobacteria [23], two phyla already identified in CW substrate [43]. Moreover, Wang et al. [25] also concluded that bioaugmentation, that is, the addition of selected MC-degrader bacteria, could improve MC removal rates.

Plant uptake can also be responsible for MC-LR removal. In the present study, analysis of MC-LR in plant tissues was not possible, but taking into consideration previous results, the removal process cannot be excluded. Pflugmacher et al. [44] reported that the aquatic macrophytes Ceratophyllumdemersum, Elodea canadensis, Vesiculariadubyana, and Phragmites australis could uptake MC-LR, and plant accumulation ranged from 1.0 to $120.0 \mathrm{pg} / \mathrm{g}$ of fresh weight after 7 days of exposure to $2.5 \mathrm{mg} / \mathrm{L}$ of ${ }^{14} \mathrm{C}-\mathrm{MC}$-LR contaminated medium. The highest uptake was by the common reed plant P. australis. Mycotoxins can also be toxic to plants, inhibiting for instance their growth [22]. However, in the present study $P$. australis seemed to resist toxins and no visible signs of toxicity where observed, with plants looking healthy through the experimental time.

Thus, MC-LR removal in CWs might have occurred through a combination of processes, such as adsorption on the CW substrates, degradation by microorganisms, and/or plant uptake.

The present study showed not only a high removal of the cyanobacteria toxin from the contaminated water, but also a high removal rate of cyanobacteria cells. Cell removal could be due to a combination of filtration, followed by adsorption and aggregation, and then metabolic activity 
of biofilm microorganisms and macrophytes, processes responsible for the removal of bacteria in CW systems [45,46]. In fact, CW efficiency for the removal of bacteria has been already shown for different domestic wastewaters (e.g., [45,46]), with percentages of removal also higher than $90 \%$ [45]. For instance, filtration through the substrate of CWs was responsible for a significant removal of faecal indicator bacteria [47]. This physical process results in the retention of bacteria in the CW system, with bacteria being adsorbed to CW substrate or plant roots. Then, bacteria can be eliminated through natural die-off (starvation or predation) [46].

From this study, we can conclude that CWs have great potential for the removal of cyanobacterial cells and cyanotoxins from contaminated fresh water. Removal of cyanobacterial cells and respective cyanotoxins by $\mathrm{CW}$ is a promising approach to treat contaminated water, especially considering the increasing number of eutrophic water bodies. In fact, recent research suggests that eutrophication and climate change are two processes that may promote the proliferation and expansion of harmful cyanobacterial blooms in fresh water, estuarine, and marine ecosystems. CWs can also be useful in reducing nutrient amounts in fresh water, and also reducing eutrophication problems.

\section{Conclusions}

Results indicate CW microcosms have the potential to treat fresh water contaminated with cyanobacterial blooms and cyanotoxins. MC-LR concentration was brought down well below the safe levels of $1 \mu \mathrm{g} / \mathrm{L}$ [48] during the treatment of contaminated lake water in CWs microcosms. Along with toxins and cyanobacteria cell removal, significant removal of organic matter and ammonium were also observed, which can be advantageous in preventing water eutrophication.

However, the processes and dynamics involved in the removal of cyanotoxins by the CWs are still unclear. More research is now needed to highlight the working dynamics of CWs in the removal pathway/fate/transformation of this pollutant. This information can then be used to improve and optimize the design and parameters of CWs, so as to achieve improved treatment efficiencies and promote $\mathrm{CW}$, application, specifically in small villages and in agricultural areas.

Supplementary Materials: The following are available online at http://www.mdpi.com/2073-4441/12/1/10/s1, Table S1: Multiple reaction monitoring (MRM) transitions and MS parameters for LC-MS/MS, Table S2: Accuracy and precision results for MC-LR analysis by LC-MS/MS.

Author Contributions: Conceptualization, A.C. and C.M.R.A.; data curation, G.B., A.C., and C.M.R.A.; formal analysis, G.B., J.A., F.O., E.P., and I.M.P.L.V.O.F.; funding acquisition, V.V., A.C., and C.M.R.A.; investigation, G.B., A.C., and C.M.R.A.; methodology, G.B., J.A., J.M., and F.O.; resources, J.M., I.M.P.L.V.O.F., V.V., A.C., and C.M.R.A.; supervision, J.M., A.C., and C.M.R.A.; validation, J.A., E.P., I.M.P.L.V.O.F., and A.C.; visualization, F.O.; writing-original draft, G.B.; Writing—review and editing, E.P., V.V., A.C., and C.M.R.A. All authors have read and agreed to the published version of the manuscript.

Acknowledgments: This research was partially supported by the Strategic Funding UID/Multi/04423/2019 through national funds provided by FCT-Foundation for Science and Technology and European Regional Development Fund (ERDF), in the framework of the programme PT2020. This project also received funding from the European Union's Horizon 2020 research and innovation programme under the Marie Skłodowska-Curie grant agreement no. 823860 .

Conflicts of Interest: The authors declare no conflict of interest.

\section{References}

1. Sivonen, K.; Jones, G. Cyanobacterial toxins. In Toxic Cyanobacteria in Water: A Guide to Their Public Health Consequences, Monitoring and Management; Chorus, I., Bartram, J., Eds.; E \& FN Spon on behalf of the World Health Organization: London, UK, 1999; Volume 1, pp. 43-112.

2. Carmichael, W.W. The cyanotoxins. In Advances in Botanical Research; Academic Press: Cambridge, MA, USA, 1997; Volume 27, pp. 211-256.

3. WWAP. Available online: http://www.un.org/waterforlifedecade/scarcity.shtml (accessed on 5 May 2019).

4. Drobac, D.; Tokodi, N.; Simeunović, J.; Baltić, V.; Stanić, D.; Svirčev, Z. Human exposure to cyanotoxins and their effects on health. Arh. Hig. Rada Toksikol. 2013, 64, 305-315. [CrossRef] [PubMed] 
5. Funari, E.; Testai, E. Human health risk assessment related to cyanotoxins exposure. Crit. Rev. Toxicol. 2008, 38, 97-125. [CrossRef] [PubMed]

6. Dawson, R.M. The toxicology of microcystins. Toxicon 1998, 36, 953-962. [CrossRef]

7. Mok, H.-F.; Dassanayake, K.B.; Hepworth, G.; Hamilton, A.J. Field comparison and crop production modeling of sweet corn and sila maize (Zea mays, L.) with treated urban wastewater and freshwater. Irrig. Sci. 2014, 32, 351-368. [CrossRef]

8. El Khalloufi, F.; El Ghazali, I.; Saqrane, S.; Oufdou, K.; Vasconcelos, V.; Oudra, B. Phytotoxic effects of a natural bloom extract containing microcystins on Lycopersicon esculentum germination, growth and biochemistry. Ecotoxicol. Environ. Saf. 2012, 79, 199-205. [CrossRef]

9. Pereira, S.; Saker, M.; Vale, M.; Vasconcelos, V.M. Comparison of sensitivity of grasses (Lolium perenne L. and Festuca rubra L.) and lettuce (Lactuca sativa L.) exposed to water contaminated with microcystins. Bull. Environ. Contam. Toxicol. 2009, 83, 81-84. [CrossRef]

10. Guzmán-Guillén, R.; Campos, A.; Machado, J.; Freitas, M.; Azevedo, J.; Pinto, E.; Almeida, A.; Cameán, A.M.; Vasconcelos, V. Effects of Chrysosporum (Aphanizomenon) ovalisporum extracts containing Cylindrospermopsin on growth, photosynthetic capacity and mineral content of carrots (Daucus carota). Ecotoxicology 2017, 26, 22-31. [CrossRef]

11. Machado, J.; Azevedo, J.; Freitas, M.; Pinto, E.; Almeida, A.; Vasconcelos, V.; Campos, A. Analysis of the use of microcystin-contaminated water in the growth and nutritional quality of the root-vegetable, Daucus carota. Environ. Sci. Pollut. Res. 2017, 24, 752-764. [CrossRef]

12. Machado, J.; Campos, A.; Vasconcelos, V.; Freitas, M. Effects of Microcystin-LR and Cylindrospermopsin on plant-soil systems: A review of their relevance for agricultural plant quality and public health. Environ. Res. 2017, 153, 191-204. [CrossRef]

13. Gutiérrez-Praena, D.; Campos, A.; Azevedo, J.; Neves, J.; Freitas, M.; Guzmán-Guillén, R.; Cameán, A.; Renaut, J.; Vasconcelos, V. Exposure of Lycopersicon Esculentum to microcystin-LR: Effects in the leaf proteome and toxin translocation from water to leaves and fruits. Toxins 2014, 6, 1837-1854. [CrossRef]

14. Pereira, A.L.; Azevedo, J.; Vasconcelos, V. Assessment of uptake and phytotoxicity of cyanobacterial extracts containing microcystins or cylindrospermopsin on parsley (Petroselinum crispum L.) and coriander (Coriandrum sativum L.). Environ. Sci. Pollut. Res. 2017, 24, 1999-2009. [CrossRef] [PubMed]

15. Gorito, A.M.; Ribeiro, A.R.; Almeida CM, R.; Silva, A.M. A review on the application of constructed wetlands for the removal of priority substances and contaminants of emerging concern listed in recently launched EU legislation. Environ. Pollut. 2017, 227, 428-443. [CrossRef] [PubMed]

16. Brix, H. Use of constructed wetlands in water pollution control: Historical development, present status, and future perspectives. Water Sci. Technol. 1994, 30, 209-223. [CrossRef]

17. Vymazal, J. Removal of nutrients in various types of constructed wetlands. Sci. Total Environ. 2017, 380, 48-65. [CrossRef] [PubMed]

18. Lesage, E.; Rousseau, D.P.; Meers, E.; Tack, F.M.; De Pauw, N. Accumulation of metals in a horizontal subsurface flow constructed wetland treating domestic wastewater in Flanders, Belgium. Sci. Total Environ. 2007, 380, 102-115. [CrossRef] [PubMed]

19. Garcia-Rodríguez, A.; Matamoros, V.; Fontàs, C.; Salvadó, V. The ability of biologically based wastewater treatment systems to remove emerging organic contaminants-A review. Environ. Sci. Pollut. Res. 2014, 21, 11708-11728. [CrossRef]

20. Meers, E.; Rousseau, D.P.; Blomme, N.; Lesage, E.; Du Laing, G.; Tack, F.M.; Verloo, M.G. Tertiary treatment of the liquid fraction of pig manure with Phragmites australis. Water Air Soil Pollut. 2005, 160, 15-26. [CrossRef]

21. Kaminski, A.; Bober, B.; Chrapusta, E.; Bialczyk, J. Phytoremediation of anatoxin-a by aquatic macrophyte Lemna trisulca L. Chemosphere 2014, 112, 305-310. [CrossRef]

22. Corbel, S.; Mougin, C.; Bouaïcha, N. Cyanobacterial toxins: Modes of actions, fate in aquatic and soil ecosystems, phytotoxicity and bioaccumulation in agricultural crops. Chemosphere 2014, 96, 1-15. [CrossRef]

23. Li, J.; Li, R.; Li, J. Current research scenario for microcystins biodegradation-A review on fundamental knowledge, application prospects and challenges. Sci. Total Environ. 2017, 595, 615-632. [CrossRef]

24. Lemes, G.A.; Kist, L.W.; Bogo, M.R.; Yunes, J.S. Biodegradation of [D-Leu(1)] microcystin-LR by a bacterium isolated from sediment of Patos Lagoon estuary, Brazil. J. Venom. Anim. Toxins Incl. Trop. Dis. 2015, $21,4$. [CrossRef] [PubMed] 
25. Wang, R.; Tai, Y.; Wan, X.; Ruan, W.; Man, Y.; Wang, J.; Yang Yand Yang, Y. Enhanced removal of microcystis bloom and microcystin-lr using microcosm constructed wetlands with bioaugmentation of degrading bacteria. Chemosphere 2018, 210, 29-37. [CrossRef] [PubMed]

26. Gorito, A.M.; Ribeiro, A.R.; Gomes, C.R.; Almeida CM, R.; Silva, A.M. Constructed wetland microcosms for removal of organic micropollutants from freshwater aquaculture effluents. Sci. Total Environ. 2018, 644, 1171-1180. [CrossRef] [PubMed]

27. Kótai, J. Instructions for Preparation of Modified, Nutrient Solution Z8 for Algae; Norwegian Institute for Water Research: Oslo, Norway, 1972; Volume 5.

28. Morais, J.; Martins, A.; Vale, M.; Vasconcelos, V. Assessment of cyanobacterial toxinogenic genotypes and estimation of toxin content in urban lakes. Fresenius Environ. Bull. 2014, 23, 1867-1873.

29. Lawton, L.A.; Edwards, C.; Codd, A. Extraction and high performance liquid chromatographic method for the determination of micro-cystins in raw and treated waters. Analyst 1994, 119, 1525-1530. [CrossRef]

30. Ramanan, S.; Tang, J.; Velayudhan, A. Isolation and preparative purification of microcystin variants. J. Chromatogr. A 2000, 883, 103-112. [CrossRef]

31. Grasshoff, K.; Ehrhardt, M.; Kremling, K. Methods of Sea-Water Analysis; VerlagChemie: Weinheim, Germany, 1983.

32. Timeanddate. Available online: https://www.timeanddate.com/weather/portugal/porto/historic?month=11\& year=2018 (accessed on 5 June 2019).

33. Almeida, C.M.R.; Santos, F.; Ferreira AC, F.; Lourinha, I.; Basto MC, P.; Mucha, A.P. Can veterinary antibiotics affect constructed wetlands performance during treatment of livestock wastewater? Ecol. Eng. 2017, 102, 583-588. [CrossRef]

34. Lee, J.; Walker, H.W. Effect of process variables and natural organic matter on removal of microcystin-LR by PAC-UF. Environ. Sci. Technol. 2006, 40, 7336-7342. [CrossRef]

35. Guittonny-Philippe, A.; Petit, M.E.; Masotti, V.; Monnier, Y.; Malleret, L.; Coulomb, B.; Laffont-Schwob, I. Selection of wild macrophytes for use in constructed wetlands for phytoremediation of contaminant mixtures. J. Environ. Manag. 2015, 147, 108-123. [CrossRef]

36. Adhikari, A.; Acharya, K.; Shanahan, S.; Zhou, X. Removal of nutrients and metals by constructed and naturally created wetlands in the Las Vegas Valley, Nevada. Environ. Monit. Assess. 2011, 180, 97-113. [CrossRef]

37. Price, T.; Probert, D. Role of constructed wetlands in environmentally-sustainable developments. Appl. Energy 1997, 57, 129-174. [CrossRef]

38. Ávila, C.; Pedescoll, A.; Matamoros, V.; Bayona, J.M.; García, J. Capacity of a horizontal subsurface flow constructed wetland system for the removal of emerging pollutants: An injection experiment. Chemosphere 2010, 81, 1137-1142. [CrossRef] [PubMed]

39. Carvalho, P.N.; Araujo, J.L.; Mucha, A.P.; Basto, M.C.; Almeida, C.M. Potential of constructed wetlands microcosms for the removal of veterinary pharmaceuticals from livestock wastewater. Bioresour. Technol. 2013, 134, 412-416. [CrossRef] [PubMed]

40. Krzeminski, P.; Tomei, M.C.; Karaolia, P.; Langenhoff, A.; Almeida CM, R.; Felis, E.; Gritten, F.; Andersen, H.R.; Fernandes, T.; Manaia, C.M.; et al. Performance of secondary wastewater treatment methods for the removal of contaminants of emerging concern implicated in crop uptake and antibiotic resistance spread: A review. Sci. Total Environ. 2019, 648, 1052-1081. [CrossRef] [PubMed]

41. Rapala, J.; Lahti, K.; Sivonen, K.; Niemelä, S.I. Biodegradability and adsorption on lake sediments of cyanobacterial hepatotoxins and anatoxin-a. Lett. Appl. Microbiol. 1994, 19, 423-428. [CrossRef] [PubMed]

42. Lahti, K.; Kilponen, J.; Kivimaeki, A. Removal of cyanobacteria and their hepatotoxins from raw water in soil and sediment columns. In Proceedings of the International Symposium on Artificial Recharge of Groundwater, Helsinki, Finland, 3-5 June 1996; pp. 187-195.

43. Santos, F.; Almeida CM, R.; Ribeiro, I.; Ferreira, A.; Mucha, A.P. Removal of veterinary antibiotics in constructed wetland microcosms-Response of bacterial communities. Ecotoxicol. Environ. Saf. 2019, 169, 894-901. [CrossRef] [PubMed]

44. Pflugmacher, S. Possible allelopathic effects of cyanotoxins, with reference to microcystin-LR, in aquatic ecosystems. Environ. Toxicol. Int. J. 2002, 17, 407-413. [CrossRef]

45. García, M.; Soto, F.; González, J.M.; Bécares, E. A comparison of bacterial removal efficiencies in constructed wetlands and algae-based systems. Ecol. Eng. 2008, 32, 238-243. [CrossRef] 
46. Wu, S.; Carvalho, P.N.; Muller, J.A.; Manoj, V.R.; Dong, R. Sanitation in constructed wetlands: A review on the removal of human pathogens and faecal indicators. Sci. Total Environ. 2016, 541, 8-22. [CrossRef]

47. Arias, C.; Cabello, A.; Brix, H.; Johansen, N. Removal of indicator bacteria from municipal wastewater in an experimental two-stage vertical flow constructed wetland system. Water Sci. Technol. 2003, 48, 35-41. [CrossRef]

48. World Health Organization Geneva. The World Health Report 1998, Life in the 21st Century: A Vision for All; Report of the Director-General World Health Organization: Geneva, Switzerland, 1998.

(C) 2019 by the authors. Licensee MDPI, Basel, Switzerland. This article is an open access article distributed under the terms and conditions of the Creative Commons Attribution (CC BY) license (http://creativecommons.org/licenses/by/4.0/). 